\title{
THE FLYING SQUAD AND THE PARAPLEGIC UNIT (PRELIMINARY REPORT)
}

\author{
By. T. M. GregG, M.D., F.R.C.P.I. ANd C. B. Wilmot, M.B., B.Ch., B.A.O. \\ National Medical Rehabilitation Centre, Dublin, Ireland
}

THE Flying Squad consists of a doctor, two nurses and two orderlies who are available to go out immediately on request to any part of Ireland to collect and bring in under supervision any acute traumatic case of paraplegia. Where respiratory trouble has been reported a physiotherapist accompanies the group. Soon after the Paraplegic Unit was opened just over two years ago a patient suffering from a cervical lesion arrived in a semi-sitting up position. The lesion has remained complete. Since then the Team has gone out to collect each acute case, usually from the local hospital. To date they have travelled out by car with the necessary equipment and come back in the local ambulance. The maximum distance so far is I60 miles from the Centre. Arrangements have now been made with the Army Air Corps which has just purchased helicopters; they will collect the doctor and nurses and fly out to collect the case.

Equipment, to deal with any emergency that might arise, is carried where necessary in sterile packs. It includes: apparatus for skull traction, packs and pillows. For respiratory difficulty there is oxygen, Ambu bag, foot-operated suction and endotracheal tubes. A Ryles tube is brought in case of paralytic ileus. There is equipment for transfusion and any drugs which may be required during the journey.

In the last two years, 32 cases have been brought in by this Team. These included 24 cervical lesions, 5 thoracic and 3 lumbar following spinal injury. Some had to be treated for shock before transfer. Of the 24 cervical cases, I9 are now incomplete and the majority (13) of them are walking or have every prospect of walking with or without walking aids. The others though incomplete are wheelchair cases-apart from their exercise periods. In 17 of the cervical cases there was radiological evidence of fracture or dislocation. In 17 cases no fracture was demonstrated. Spondylosis was found in 5 of these. Two of the complete lesions died some weeks after admission, one a $\mathrm{C}_{5}$ lesion aged 50 years with a history of coronary infarction from another coronary thrombosis. The second, a $\mathrm{C}_{4}$ lesion aged 58 years, went slowly downhill with a chest infection, diabetes insipidus-like state and stomatitis. Four of the five thoracic lesions were complete from the start and there was no change after admission.

\section{DISTRIBUTION OF CASES BROUGHT IN BY FLYING SQUAD}

It is interesting to note that although this Unit is of recent foundation and initially not well known, in I8 cases the team were notified and set out within 24 hours of the injury. The arrival of an efficient Team at a local hospital makes an impact, and in these cases where there was a delay in the first instance in requesting admission to the Unit, subsequent cases were notified immediately. In addition to earning goodwill and ensuring transfer, this dramatic attention to detail in the 
early care of these patients focuses attention locally on the importance of detailed supervision in a way that no learned lecture or paper can do.

\begin{tabular}{|c|c|c|c|c|c|}
\hline & \multicolumn{2}{|c|}{ On admission } & \multicolumn{2}{|c|}{ Later } & \multirow{2}{*}{$\begin{array}{l}\text { Spinal injury. } \\
\text { No C.N.S. } \\
\text { lesions }\end{array}$} \\
\hline & Incomplete & Complete & Incomplete & Complete & \\
\hline Cervical & I5 & 8 & I9 & 4 & I \\
\hline Dorsal & I & 4 & I & 4 & \\
\hline Lumbar & 2 & & 2 & & I \\
\hline
\end{tabular}

TWO CASES DESERVE PARTICULAR ATTENTION:

I. A man aged 50 years was seen in a local hospital soon after a fall. There was an incomplete cervical lesion. The patient was too shocked to move and in fact this is the only case where we delayed for 24 hours before transferring him. Unfortunately we were unable to leave the trained nursing staff of the Paraplegic Unit. When we collected the patient the following day the lesion was complete. The halter-type traction which had been used had not immobilised the cervical fracture.

2. A man aged 32 years with a complete lesion $\left(\mathrm{C}_{5}\right)$ was brought slowly by ambulance 160 miles without incident on the day of his accident. He did well, but five days later, without warning, the level of the lesion rose higher until eventually he stopped breathing. Artificial respiration followed by tracheotomy and positive pressure breathing for one week saved him. This case emphasises the advantage of early admission to a specialised Unit.

This emergency approach immediately following the accident by a skilled Team is, we feel, a logical one. It is at this stage that the maximum effort should take place. Rogers (1952) stated that Io per cent. of his cases of traumatic paraplegia developed signs of cords damage not immediately but some time after the accident. We have had a suprisingly large proportion of incomplete cervical lesions. We are of the opinion that this is, at least in part, due to the painstaking work of the 'Flying Squad'. 